Lancereaux says, "they gain in depth what they lose in extent." In a case I saw some little time ago the bodies of the vertebræ, covered only by the anterior common ligament, were exposed, and in this case the ulcer extended further than is usual-i.e., down to the level of the epiglottis and up to almost the top of the pharynx. The late Sir Morell Mackenzie ${ }^{3}$ mentioned a case that was under his care where the patient had a deep ulcer on the posterior wall of the pharynx and on the right side, lost more than a quart of blood, and shortly afterwards expectorated the transverse process of the second cervical vertebra, the hæmorrhage, in his opinion, probably coming from the vertebral artery.

The deep ulcers are often in an early stage almost painless, but later, when the ulceration extends in depth, they cause much pain and may seriously interfere with deglutition. Unless they are treated promptly and appropriately very serious consequences may result, such as contractions, adhesions of the soft palate to the pharynx, \&c., hæmorrhage, and malnutrition from painful deglutition. It is essential that both the constitutional and the local treatment be continued antil every vestige of the disease has disappeared. Iodide of potassium should be given in doses beginning at five grains three times a day and increased up to thirty or forty grains daily, and should be continued for some time after the healing of the vicers. It is best given well diluted with water and in conjunction with quinine.

Locally it is of great importance to thoroughly cleanse the ulcers before applying the astringent, and the routine used is: (1) to thoroughly spray the foul surface and surroundings of the ulcer with an alkaline solution and then to wipe it as clean as possible with pledgets of wool on holders ; (2) to paint the affected part with a solution of cocaine of the strength of twenty grains to the ounce ; and (3) to thoroughly paint the ulcer with a brush dipped in the solution of copper sulphate, twenty grains to one ounce. The patient is ordered some simple gargle, as gargarismus boracis, to cleanse his pharynx out with, and the treatment is renewed daily or every other day. It is astonishing how quickly the ulceration ceases, the surface and surroundings of the ulcer losing their angry look and the foul discharge ceasing, and in a few days healing is well advanced.

If it is a matter of inconvenience to the patient to see his medical adviser daily, he can easily be taught how to use the sulphate of copper himself, taking care that he be instructed to thoroughly cleanse the surface of the alcer and to paint it with cocaine before applying the astringent. One of the disadvantages in the use of the galvano-cautery in these cases is that the surgeon has to apply it himself daily, often a matter of difficulty for the patient to arrange for.

For permission to use these notes $I$ have to thank Dr. de Havilland Hall.

CASE 1.-A man aged twenty-seven first attended as an out-patient at Westminster Hospital on Oct. 12th, 1893. Four years ago he noticed a disagreeable thick discharge from both anterior nares; this got worse, but he neglected it till twelve months ago, when he attended as an out-patient and got much better. Then he left off treatment for a time, but two months ago the discharge returned, being worse than before. There was a distinct history of syphilis. On examination, large masses of crusts were seen in the vares; the septum was perforated, and there was ulceration of a superficial character on the fauces. He was treated with iodide of potassium and locally with collunarium sodii, and got so much better that he did not trouble to come again after Dec.7th. On May 3rd, 1894, he came back again with a large, very deep ulcer in the posterior wall of the pharynx, which was covered with foul, yellowish sloughs; all the septum nasi was destroyed, and the ulceration actively extending. The surface of the ulcer was sprayed with alkaline solution, painted with cocaine, and then sulphate of copper was applied thoroughly. Iodide of potassium and boracic gargle were ordered. This treatment was repeated on May 8th, when the ulcer was found to be much improved. On the 10th the ulcer was quite clean and healthy, and rapidly healing. Sulphate of copper was again applied.

CASE 2.-A woman aged twenty-eight attended as an out-patient in October, 1893, for syphilitic disease of the throat. Nearly the whole of the soft palate was occupied with a deep, irregular ulcer with undermined edges and covered with a dirty, tenacious, yellowish slough; this cansed no pain. There were one or two small ulcers on the posterior wall of the pharynx as well. The ulcers were treated in

3 Transactions of the Pathological Society, vol. xx., p. 283. the same way with sulphate of copper, and in ten days had quite healed up, leaving, however, a great deal of deformity and contraction.

CASH 3.-A man aged forty attended as an out-patient on Jan. 11th, 1894, for sore throat and an ulcer on his tongue; six years ago he had a chancre, followed by rash, sore throat, \&c., and he had been under treatment at various times for it. During the last month he had been troubled with ulceration of the tongue and pharynx. On examination of his tongue a large, deep, irregular foul ulcer was seen occupying the greater part of the anterior third of the organ; the surface of the ulcer was covered with a dirty slough, and the edges were rather heaped up and inflamed; there were no enlarged glands and very little pain. A small superficial ulcer occupied the posterior wall of the pharynx. Both ulcers were thoroughly cleansed, cocainised, and painted with sulphate of copper. By the commencement of February both ulcers had healed completely.

CASE 4.-A woman thirty-two years of age attendzd as an out-patient on Feb. 1st, 1894. There was a history of syphilis seven years ago. Ulceration of the throat was first noticed two years ago and since then she had had trouble of the same sort frequently. On examination a large, deeply excavated, dirty ulcer was seen occupying the soft palate, and the pillars of the fauces were much swollen. She was ordered quinine and iodide of potassium, and the ulcer was cleansed and treated with sulphate of copper. She was shown how to use the astringent herself, and by the beginning of March the ulcer had healed, leaving, however, a good deal of contraction and some adhesion between the soft palate and the pharynx.

CASE 5.-A woman aged thirty-one attended as an outpatient on Feb. 22nd, 1894. There was a history of sorethroat three years ago. The patient got better, then one year ago got worse again, and has been under treatment for it every now and then for the last four or five months. There was difficulty in swallowing from pain, and she complained of nasal obstruction. On examination a very extensive and very deep tertiary ulcer of the posterior wall of the pharynx and the soft palate was seen; the surface was very foul and covered with a slough like wet chamois leather; the patient's general health was very bad. Fifteen grains of iodide of potassium three times a day were ordered, and the ulcers were treated in the same way as the other cases. A boracic gargle was ordered as a mouth wash. On Feb. 26th the treatment was repeated ; the ulcers were much cleaner. On March 8th the ulcers were nearly healed, and the general health was much improved, but there were extensive adhesions between the soft palate and the pharynx, partially cutting off the naso-pharynx from the oro-pharynx.

Queen Anne-street, Cavendish-square, W.

\section{THE FORMATION OF A SUPRA-PUBIC URETHRA.}

By C. W. MANSELL MOULLIN, M.D., F.R.C.S. ENG., SURGEON TO THE LONDON HOSPITAL.

THE formation of a permanent supra-pubic channel leading from the bladder is an old and well-known means for evading the ills attendant upon advanced urethral obstruction. In many instances it affords almost the only prospect of relief ; the attempts, however, that have hitherto been made to place the opening nnder the patient's control have not met with an equal degree of success. Whether formed by puncture or by formal cystotomy, the channel is only $a_{1}$ sinus leading obliquely downwards into the bladder, lined by granulation tissue and constantly tending to contract. To ensure comfort a costly apparatus requiring perpetua: attention must be worn night and day. 1 simp. tube provided with a stopcock may answer for a time bnt, though leakage around it can be prevented by adopting Professor Wiley Broome's suggestion of cutting a screw thread on its outer surface, the diminution in the carrying capacity of the bladder that follows cannot. A rubber appliance with a portable urinal strapped on to the leg may suffice for an old man in the last stage of eniargement of the prostate, leading an almost sedentary life; in the case of a younger one it is a serious hindrance, and in many instances the knowledge that something of the kind 
will be necessary for the rest of life prevents the patient from giving his consent until the condition is almost hopeless. Nussbaum and others have tritd to make use of the recti and pyramidales as a spbincter. The opening may be made either between them or through one of them, a little to one side of the median line, the fibres being simply separated in the direction of their length, without division. The power these muscles possess is undoubted. If the finger is placed between the two recti, just above the pubes, it is firmly gripped when the patient strains or vomits ; but in old people with enlargement of the prostate the muscular power is very feeble, and in all cases alike there is the disad. vantage that the sphincter action cannot be brought into play without counteracting its own influence by the way in which the abdominal pressure is increased at the same time. Hunter McGuire ${ }^{l}$ has improved upon this considerably by making the channel longer and valvalar. The bladder is opened at the lowest available median point, the upper end of the abdo. minal incision is left open, and the rest is sutured accurately. This leaves a fistula two or three inches in length, the walls of which are kept in apposition by the pressure of the abdominal viscera, so that the patient can retain or pass his urine at will. The bladder is not attached to the abdominal wall in any way, as this interferes with the length of the artificial urethra. Morris of New York ${ }^{2}$ recommends that the fistula should be lined with skin. Two ribbons of skin and subcutaneous tissue, each about three inches long and one-third of an inch wide, are dissected away from the sides of the abdominal incision. The pubic ends of the ribbons are left attached; the upper ones are separated and are sutured with cargut to the mucous membrane of the bladder, each on its respective side. The temporary sutures that bold the bladder up are cut, and as the bladder drops down it takes with it two ribbons which lie face to face, and form between them a soft urethra lined with skin. A short rubber drainage-tube is left in the bladder for forty-eight hours. The patient is able, when the wound is sound, to retain his urine or pass it at will, substituting a glass drainage-tube for the penis by pressing one end of it against the supra-pubic meatus.

I have combined these two methods with a certain amount of success. The patient was a man forty-five years of age, who had suffered from exceedingly extensive extravasation of urine. Two inches of the urethra were destroyed, preventing anything of the nature of a plastic operation, and the skin over the root of the penis bad sloughed away. When the wounds were sound the urine came by several fistule through the perineum. Supra-pubic cystotomy was performed, and two ribbons of skin were dissected up from the sides according to Morris's plan ; but the upper ends were left attached, and the lower were sutured to the mucons membrane of the bladder, so as to secure the advantage of a lnng valvular urethra as well. The wounds healed somewbat slowly, owing to the fisct that the sides bad to close in by granulating. At the end, however, the result was very satisfactory. The patient could hold his urine for three bours at a time. The perineal fistulæ almost closed, so that only a little moisture came from them, and by placing the end of a pitce of rabber tubing in the depression, at the bottom of which lay the external orifice, he conld direct the stream and empty his bladder as he wished. The patient was advised to pass a catheter every evening through the new channel and to allow it to remain in for balf an hour; but, unfortunately, this was not carried out. Some weeks later an angle developed in the new urethra, where the cutaneous flans joined the mucous membrane. The superficial portion of the channel ran upwards towards the umbilicus, the deep part almost directly backwards, and some phosphatic material collected at the bend. This was easily put right by inserting a drainage-tube for a few days, but the necessary precautions were not kept up; a fresh abscess formed in the cicatricial tissue that filled the perineum, and the supra-pubic opening was neglected and allowed to contract. Had a catheter been introduced once during the twenty.four hours, or a plug been worn at night, I am convinced that the patier $t$ would have retained the power he possessed for a few weeks of being able to hold or pass his unine at will, withont the necessity for wearing an apparatus permanently. Dr. Morris bas since written to me that on another occasion he would make the flaps a good deal wider-a suggestion that appears to me to be valuable.
The operation is necessarily more lengthy than supra-pubic puncture, and convalescence is slower; the wound that it leaves is more extensive. It is therefore not to be recom. mended for the aged, or in cases of disease in which there is no reasonable prospect of active life. In such puncture is to be preferred. Some little time ago I tapped the bladder supra pubes in a woman who was suffering from advanced carcinoma involving the urethra. A simple apparatus similar to that described by $\mathrm{Mr}$. Buckston Browne ${ }^{3}$ was adjusted, and she was enabled with the minimum of risk to spend the rest of her days in comparative comfort. When it is required in younger men there can be no doubt, it seems to me, as to the great advantage to be obtained by adopting this modification.

Wimpole-street, $w$.

\section{THE PRINCIPLES OF THERAPEUTIC PROGRESS AND SUCCESS.}

B Y GORDON SHARP, M.B. EDIN.,

LATE RESEaRCh STUDENT IN PHARMaCOLOGY IN THE OWENS COLLEg, VICTORIA UNIVERSITY, MANCHESTER.

Whex Francis Bacon promulgated his new philosophy it gave in process of time a great impetus to science in general. His philosopby was one of action, as opposed to the old philosophy which was one of inaction, when men were expected to sit down and calmly await till it pleased the Fates to bring about some great discovery. The old philosopher-scientist deemed it beneath his dignity to explore into hidden parts, and all he thought himself entitled to do was to sit and imagine, and then to wait till in some mysterious way his thoughts bad become accomplished facts. This was where he erred. But the new philosopher erred in the opposite direction in depending too much, or rather altogether, on experiment, and in placing no dependence on deduction. A time came when it was found that neither the old nor the new philosophy was true, but that for the advarcement of science we must employ, so to speak, a mixture of the two, and by these means arrive at the trutb. What has taken place in general science has been repeated in the world of therapentics. For a long number of years the empirical, experimental, or observational method held sway. But a revolution came when the science of pharmacolozy was established, and by pharmacology I mean the application of physiology and physiological methods to tbe investigation of the action of drugs on the animal organism. Pharmacology really only found itself established when Professors Crum Brown and T. R. Fraser published their essays showing the relationship between cbemical constitution and physiolngical action. The very title of their essays sbows that in this great field of therapeutics we can employ "deductive mathematical reasoning." It is to be observed, however, that the two scientists just named proved their deductions by experiment, so that they have answered all the requirements for scientific advance.

From what bas been said it will be seen that for a century or two the new philosophy (empirical) has been applied in the study of therapeutics, while it is only recently that it has been combined with the old. At the present time the tendency is for pharmacologists to cultivate the deductive side too much. I do not say that they leave out the experimental side altngether, but they pay too little attention to it and "verify" upon too little evidence. One can find an illustration from the so-called synthetical remedjes. These are built up with the view of throwing in a bypnotic, analgesic, or antipyretic element, as the case may be. The designer wishes them to contain certain bodies to produce a certain effect. He tries his remedy and, being prejudiced in its favour, frequently states that it does what he bas wished it to do. Others use the remedy, but with different results, and after various changes it is finally cast aside as useless, till, perbaps, some less prejudiced individual and more careful observer finds it to possess some tberapeutic action undreamed of hy the deviser. Although we may indicate the lines on which therapeutic investigation is to be carried on, so many points of error occur that the experiments have to be repeated again and again, and exterded over a very long period of time. Man is a variable 